\title{
Locally advanced breast cancer in elderly patients
}

\author{
Jana Hornovaa , Zbynek Bortlicek ${ }^{b}$, Petra Majkova ${ }^{b}$, Jitka Abrahamovaa , Drahomira Kordikovaa, Zuzana Donatovaa, \\ Martin Kupec ${ }^{\mathrm{a}}$, Ludmila Boublikova ${ }^{\mathrm{a}}$, Josef Dvorak ${ }^{\mathrm{a}}$, Radek Zapletal ${ }^{\mathrm{a}}$, Tomas Buchler ${ }^{\mathrm{a}}$
}

\begin{abstract}
Background. Although locally advanced breast cancer ( $L A B C)$ is more common in the elderly population, there is little data on the clinical characteristics and survival of these patients. The aim of the present study was to compare different factors affecting survival in elderly patients with $L A B C$.

Methods. Retrospective analysis was carried out on a cohort of 80 patients aged 70 to 96 years, diagnosed with LABC defined as T3 N1, T4 N0, any N2 or N3, and M0. The prognostic impact of selected clinical parameters including age, comorbidities, tumour grade, HER2 status, tumour stage, local therapies, and systemic treatments was studied.

Results. The median age of the patients was 79 years. The majority $(n=53 ; 66 \%)$ had at least one significant comorbidity according to the Charlson score evaluation. The median overall survival was 50.6 months. As expected, hormonal therapy was the dominant mode of systemic treatment, but $24 \%$ also received at least one line of chemotherapy. Local therapies including surgery and/or radiotherapy were applied in $58 \%$ of patients.
\end{abstract}

Conclusions. The diagnosis of $L A B C$ in the elderly is associated with poor prognosis. Age and serious comorbidities were negative prognostic factors.

Key words: breast cancer, Charlson score, elderly, retrospective analysis, survival

Received: November 9, 2016; Accepted with revision: March 17, 2017; Available online: March 30, 2017

https://doi.org/10.5507/bp.2017.011

${ }^{a}$ Department of Oncology, $1^{\text {st }}$ Faculty of Medicine, Charles University and Thomayer Hospital, Prague, Czech Republic 'Institute of Biostatistics and Analyses, Masaryk University, Brno, Czech Republic

Corresponding author: Tomas Buchler, e-mail: tomas.buchler@ftn.cz

\section{INTRODUCTION}

Breast cancer is the most common cancer in women in developed countries. In the Czech Republic, approximately $35 \%$ of breast cancer patients are diagnosed at the age of 70 years or more. Furthermore, the proportion of patients diagnosed after the 80th year of life has increased by $50 \%$ over the last two decades according to the Czech Cancer Registry ${ }^{1}$.

Age itself is an adverse prognostic factor for overall survival (OS) in breast cancer ${ }^{2,3}$. One of the reasons for the poor outcome is the fact that elderly women with breast cancer present more frequently with locally advanced breast cancer (LABC) without distant metastases at the time of diagnosis clearly seen in epidemiology reports (Table 1) $\left(\right.$ ref. $^{1}$ ).

Advanced age is generally associated with a lower exercise tolerance, increased incidence of comorbidities, loss of self-sufficiency and deterioration of cognitive function. Clinical guidelines for breast cancer are in agreement that treatment decisions should not be based on age alone while recognising that overall health status plays an important role in the choice of treatment ${ }^{4,5}$. It is clear that therapeutic interventions are not applied with the same intensity in the elderly as in younger patients ${ }^{6-8}$. In addition, as the number of elderly patients in most clinical trials is limited, there are few therapeutic recommendations that rely on evidence-based data.

Several definitions are used for the elderly population in oncology. The limit of 70 years was selected for the present study in accordance with the recommendations published by the European Society for Medical Oncology ${ }^{9}$. Our principal objective was to identify factors associated with overall survival in patients with LABC $\geq 70$ years of age.

\section{METHODS}

\section{Study design and patients}

LABC was defined as T3 N1, T4 N0, any N2 and N3, and M0. All patients were diagnosed and/or treated at the Department of Oncology, Thomayer Hospital, Prague, Czech Republic, during the years 2004-2014. Data on the primary tumour, patient characteristics and therapy were acquired from the medical records to retrospectively analyse treatment strategies and outcomes. As only retrospective observational data were used, the study was exempt from approval by the ethics committee.

\section{Statistical analysis}

Clinical variables including age, TNM stage, tumour grade, HER2 status, Charlson comorbidity index ${ }^{10}$ the application of systemic therapies (chemotherapy, targeted therapy and/or hormonal therapy) and local therapies (surgery and/or radiotherapy) were analysed. OS was defined as the time from the date of diagnosis to the date of death from any cause and estimated using the KaplanMeier method. Two-sided Fisher's exact test was used to compare the baseline characteristics for the subgroups. 
Univariate and multivariable Cox regression analysis was used to examine the association between patient characteristics and overall survival.

\section{RESULTS}

\section{Baseline characteristics and treatment}

We identified 80 female patients aged 70 and older with LABC without distant metastases in the patient database. Baseline patient characteristics for subgroups aged 70 to 79 years and $\geq 80$ years are summarised in Table 1 .

The median age of the patients was 79 years (range $70-96$ years $)$. The majority of patients $(n=53 ; 66 \%)$ had at least one significant comorbidity as defined in the Charlson score evaluation. As expected, $85 \%$ of patients had tumours expressing oestrogen receptors. A significant proportion of the patients had HER2 positive tumours $(n=21 ; 26 \%)$, and the percentage of HER2 positive tumours rose to $33 \%$ in the patients $\geq 80$ years of age.

Patients $\geq 80$ years had higher mean Charlson score and lower probability of locoregional therapies and chemotherapy compared to patients aged 70 to 79 years.

Local or locoregional treatments were applied in 46 (58\%) patients, including surgery in $38(48 \%)$ patients and radiotherapy in $38(48 \%)$ patients. In accordance with the diagnosis of LABC, only three patients were treated with breast-conserving surgery ( $8 \%$ of all operated patients). Twenty-nine patients (36\%) received both local treatment modalities.

Although primary surgery is not the recommended therapy for most LABC patients, patients treated with primary radical surgery $(n=15)$ had similar survival (median OS 69.7 months, 95\% CI 50.6-92.1 months) as patients who had surgery after previous neoadjuvant chemotherapy or hormonal therapy ( $\mathrm{n}=14$; median OS 65.2 months, 95\% CI 48.6-67.2 months). In the remaining patients treated with surgery, the procedure was not carried out with the intention of radicality.

Hormonal therapy was the most frequent treatment modality, used in 75 (94\%) of patients. Seventy percent of patients received at least one line of aromatase inhibitors during the disease course. Chemotherapy was applied in $19(24 \%)$ of patients. The most commonly used drug was vinorelbine ( 9 patients), followed by anthracyclines ( 8 patients) and taxanes ( 5 patients).

\section{Overall survival}

As of the data cut-off date, forty-seven (59\%) of patients had died. The cause of death was stated as canceror cancer treatment-related in 23 patients ( $49 \%$ of deaths). In the 22 patients aged $\geq 80$ years who had died by the data cut-off date, thirteen deaths (59\%) were recorded as cancer- or cancer treatment-related. However, because cancer and its treatment can contribute to the deterioration of other conditions in the elderly, these results must be interpreted with caution.

Median survival was 50.6 months (Fig. 1). The results of univariate analysis of prognostic factors are shown in Table 2. Of the analysed clinical parameters, age and the presence of severe comorbidities measured as the Charlson score were significantly associated with OS. Multivariable analysis showed that age is the most important prognostic factor for overall survival (Table 4). However, the multivariable analysis was limited by strong correlations between some of the evaluated parameters and incomplete data.

\section{DISCUSSION}

The present retrospective, single-centre study has confirmed poor overall survival of elderly patients with LABC and identified the presence of severe comorbidities as the principal adverse risk factor for survival.

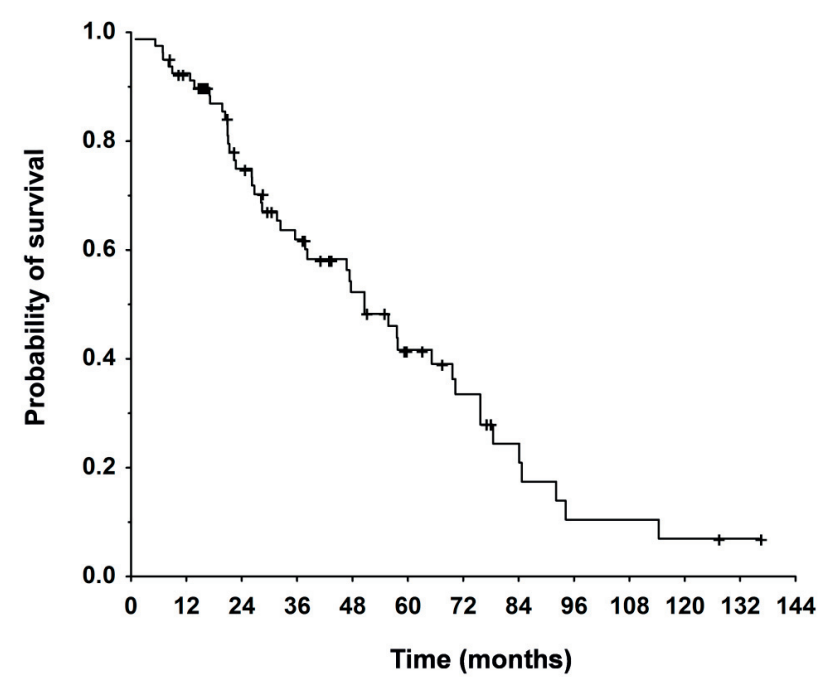

Fig. 1. Overall survival from the date of diagnosis.

Table 1. Proportion of TNM stages at diagnosis for patients diagnosed with breast cancer in 2013 according to the Czech Cancer Registry ${ }^{1}$.

\begin{tabular}{lcccc}
\hline Stage & $\begin{array}{c}\text { All patients } \\
(\mathrm{n}=7140)\end{array}$ & $\begin{array}{c}\text { Patients }<70 \text { years } \\
(\mathrm{n}=4685)\end{array}$ & $\begin{array}{c}\text { Patients } \geq 70<80 \text { years } \\
(\mathrm{n}=1489)\end{array}$ & $\begin{array}{c}\text { Patients } \geq 80 \text { years } \\
(\mathrm{n}=966)\end{array}$ \\
\hline I (\%) & 47.5 & 50.8 & 49.8 & 28.2 \\
II (\%) & 32.2 & 32.1 & 29 & 37.8 \\
III (\%) & 10.8 & 9.8 & 10.7 & 16 \\
IV (\%) & 6.6 & 5.7 & 7.7 & 9.7 \\
unknown (\%) & 2.8 & 1.7 & 2.8 & 8.3 \\
\hline
\end{tabular}


Table 2. Baseline patient characteristics.

\begin{tabular}{|c|c|c|c|c|}
\hline \multirow{2}{*}{ Characteristics, n (\%) } & & \multicolumn{2}{|c|}{ Age at diagnosis } & \multirow[b]{2}{*}{$P$} \\
\hline & & $70-79$ years & $80+$ years & \\
\hline Age at diagnosis & median (range) & 76 years $(70-79)$ & 84 years $(80-96)$ & - \\
\hline \multirow[t]{3}{*}{ Charlson score } & 0 & $19(46.3)$ & $8(20.5)$ & 0.018 \\
\hline & $1-2$ & $15(36.6)$ & $26(66.7)$ & \\
\hline & 3 & $7(17.1)$ & $5(12.8)$ & \\
\hline \multirow[t]{4}{*}{ Tumour grade } & grade 1 & $1(2.4)$ & $0(0.0)$ & \\
\hline & grade 2 & $18(43.9)$ & $22(56.4)$ & 0.716 \\
\hline & grade 3 & $8(19.5)$ & $10(25.6)$ & \\
\hline & unknown & $14(34.1)$ & $7(17.9)$ & \\
\hline \multirow[t]{3}{*}{ HR status } & negative & $3(7.3)$ & $1(2.6)$ & 0.223 \\
\hline & positive & $30(73.2)$ & $38(97.4)$ & \\
\hline & unknown & $8(19.5)$ & $0(0.0)$ & \\
\hline \multirow[t]{3}{*}{ HER2 status } & negative & $20(48.8)$ & $22(56.4)$ & \\
\hline & positive & $8(19.5)$ & $13(33.3)$ & 0.510 \\
\hline & unknown & $13(31.7)$ & $4(10.3)$ & \\
\hline \multirow[t]{3}{*}{ Exulcerated tumor } & no & $27(65.9)$ & $18(46.2)$ & \\
\hline & yes & $9(22.0)$ & $14(35.9)$ & 0.100 \\
\hline & unknown & $5(12.2)$ & $7(17.9)$ & \\
\hline \multirow[t]{4}{*}{ Stage of the primary tumor } & $2 \mathrm{~b}$ & $4(9.8)$ & $2(5.1)$ & \\
\hline & $3 a$ & $12(29.3)$ & $4(10.3)$ & 0.070 \\
\hline & $3 b$ & $21(51.2)$ & $31(79.5)$ & \\
\hline & $3 \mathrm{c}$ & $4(9.8)$ & $2(5.1)$ & \\
\hline \multirow[t]{2}{*}{$\mathrm{T}$ - size of the primary tumor } & $\mathrm{T} 2$ or $\mathrm{T} 3$ & $19(46.3)$ & $8(20.5)$ & 0.070 \\
\hline & $\mathrm{T} 4$ & $22(53.7)$ & $31(79.5)$ & \\
\hline \multirow[t]{2}{*}{ Operated } & no & $10(24.4)$ & $32(82.1)$ & $<0.0001$ \\
\hline & yes & $31(75.6)$ & $7(17.9)$ & \\
\hline \multirow[t]{2}{*}{ Radiotherapy } & no & $12(29.3)$ & $30(76.9)$ & $<0.0001$ \\
\hline & yes & $29(70.7)$ & $9(23.1)$ & \\
\hline \multirow[t]{2}{*}{ Any local therapy } & no & $7(17.1)$ & $27(69.2)$ & $<0.0001$ \\
\hline & yes & $34(82.9)$ & $12(30.8)$ & \\
\hline \multirow[t]{2}{*}{ Chemotherapy } & no & $22(53.7)$ & $39(100.0)$ & $<0.0001$ \\
\hline & yes & $19(46.3)$ & $0(0.0)$ & \\
\hline \multirow[t]{2}{*}{ Aromatase inhibitors } & no & $12(29.3)$ & $12(30.8)$ & 1.0000 \\
\hline & yes & $29(70.7)$ & $27(69.2)$ & \\
\hline \multirow[t]{2}{*}{ Any hormonal therapy } & no & $4(9.8)$ & $1(2.6)$ & 0.3597 \\
\hline & yes & $37(90.2)$ & $38(97.4)$ & \\
\hline
\end{tabular}

Locally advanced breast cancer (LABC) is common in the elderly. According to the Czech Cancer Registry data available online, the proportion of patients diagnosed with stage III breast cancer increases with age, with a marked difference between women aged $70-79$ years and those aged 80 years or more. This is also reflected in the inverse trend for patients diagnosed in stage I (Table 1) (ref. ${ }^{1}$ ). The reasons for higher proportion of LABC at diagnosis in the elderly are probably related to lower uptake of health care recommendations, such as regular gynaecology exams and screening mammography. However, data from the present cohort indicate that an increase in the proportion of high-grade tumours in the population aged 80 years or more may play a role. The finding of relatively high proportion of HER2 positive tumours in the present $\mathrm{LABC}$ cohort requires further validation as the expression of this adverse prognostic marker is expected to be low in the elderly population ${ }^{11}$.

Mortality in the described cohort of patients with LABC was high. The rate of cancer as primary death cause was markedly higher than that published for unselected populations of elderly women with breast cancer in whom it decreases below $40 \%$ by the age of 80 years $^{6}$. The median OS of 50.6 months in the present study is in close agreement with data published for stage III patients ${ }^{12}$.

The reasons for the adverse survival include the overall poor condition and high incidence of severe comorbidities in this age group of patients, but also prejudices such as ageism and nihilism about the effectiveness of cancer therapy in the geriatric population ${ }^{7}$. Elderly patients with cancer face unique challenges in their struggle with the disease. Age, higher treatment complication rates, and 
Table 3. Univariate analysis of baseline characteristics predictive for overall survival.

\begin{tabular}{|c|c|c|c|c|c|}
\hline \multirow{2}{*}{ Characteristic } & \multirow{2}{*}{ Categories } & \multicolumn{3}{|c|}{ Overall survival } & \multirow[b]{2}{*}{$P$} \\
\hline & & $\mathrm{n}(\%)$ & $\begin{array}{c}\text { Median OS } \\
\text { months }(95 \% \mathrm{CI})\end{array}$ & HR $(95 \% \mathrm{CI})$ & \\
\hline \multicolumn{2}{|l|}{ All patients } & 80 & $50.6(39.4-61.8)$ & - & - \\
\hline \multirow[t]{2}{*}{ Age } & $\geq 80$ years & $39(48.8)$ & $31.6(19.0-44.3)$ & $2.55(1.40-4.65)$ & 0.002 \\
\hline & $<80$ years & $41(51.2)$ & $78.5(51.4-105.5)$ & & \\
\hline \multirow[t]{2}{*}{ Charlson score } & $1-3$ & $53(66.3)$ & $38.2(20.1-56.4)$ & $2.76(1.35-5.65)$ & 0.006 \\
\hline & 0 & $27(33.8)$ & $92.1(44.7-139.5)$ & & \\
\hline \multirow[t]{2}{*}{ Tumor grade } & grade $3-4$ & $18(30.5)$ & $38.2(11.7-64.7)$ & $1.31(0.62-2.75)$ & 0.484 \\
\hline & grade $1-2$ & $41(69.5)$ & $50.6(46.0-55.3)$ & & \\
\hline \multirow[t]{2}{*}{ HR status } & negative & $4(5.6)$ & $38.2(29.5-47.0)$ & $1.08(0.25-4.59)$ & 0.921 \\
\hline & positive & $68(94.4)$ & $50.6(38.9-62.3)$ & & \\
\hline \multirow[t]{2}{*}{ HER2 status } & negative & $42(66.7)$ & $50.6(29.2-72.1)$ & $1.03(0.49-2.16)$ & 0.942 \\
\hline & positive & $21(33.3)$ & $55.8(46.1-65.4)$ & & \\
\hline \multirow{2}{*}{ Exulcerated tumor } & yes & $23(33.8)$ & $37.7(0.0-91.1)$ & $1.16(0.58-2.32)$ & 0.671 \\
\hline & no & $45(66.2)$ & $55.8(43.9-67.7)$ & & \\
\hline \multirow[t]{2}{*}{ T3 vs. T4 } & $\mathrm{T} 4$ & $53(66.3)$ & $46.8(25.3-68.2)$ & $1.80(0.93-3.50)$ & 0.082 \\
\hline & T3 & $27(33.8)$ & $57.6(40.8-74.5)$ & & \\
\hline \multirow[t]{2}{*}{ Stage } & $3 b-3 c$ & $58(72.5)$ & $47.7(25.3-70.0)$ & $1.61(0.81-3.19)$ & 0.177 \\
\hline & $2 b-3 a$ & $22(27.5)$ & $50.6(38.4-62.8)$ & & \\
\hline
\end{tabular}

Table 4. Multivariable Cox analysis of baseline characteristics predictive for overall survival.

\begin{tabular}{|c|c|c|c|c|}
\hline Characteristic & Categories & n $(\%)$ & $\operatorname{HR}(95 \% \mathrm{CI})$ & $P$ \\
\hline \multirow[t]{2}{*}{ Age } & $\geq 80$ years & $23(54.8)$ & $4.76(1.22-18.61)$ & 0.025 \\
\hline & $<80$ years & $19(45.2)$ & 1.00 & \\
\hline \multirow[t]{2}{*}{ Charlson score } & $1-3$ & $27(64.3)$ & $3.09(0.64-15.05)$ & 0.162 \\
\hline & 0 & $15(35.7)$ & 1.00 & \\
\hline \multirow[t]{2}{*}{ Tumor grade } & grade $3-4$ & $16(38.1)$ & $0.86(0.34-2.20)$ & 0.751 \\
\hline & grade $1-2$ & $26(61.9)$ & 1.00 & \\
\hline \multirow[t]{2}{*}{ HER2 status } & negative & $29(69.0)$ & $1.12(0.38-3.29)$ & 0.837 \\
\hline & positive & $13(31.0)$ & 1.00 & \\
\hline \multirow{2}{*}{ Exulcerated tumor } & yes & $13(31.0)$ & $0.79(0.25-2.52)$ & 0.692 \\
\hline & no & $29(69.0)$ & 1.00 & \\
\hline \multirow[t]{2}{*}{ Stage } & $3 b-3 c$ & $31(73.8)$ & $0.51(0.17-1.53)$ & 0.228 \\
\hline & $2 b-3 a$ & $11(26.2)$ & 1.00 & \\
\hline
\end{tabular}

psychosocial stress have a negative impact on coping with the diagnosis as well as on the likelihood of treatment completion.

In the elderly population, the benefit of local therapy should be carefully weighed against the risk of possible postoperative complications. Nevertheless, the risk of possible undertreatment has been suggested by many authors $^{6-8}$. One of the findings of the present study was that patients $\geq 80$ years had lower probability of locoregional therapies and chemotherapy compared to patients aged 70 to 80 years (Table 2). These differences are likely the result of increasing prevalence of severe comorbidities with advancing age.

A cohort similar to the present one has been published by Sanguinetti and collaborators. The patients were nearly all treated with surgery but few of them received adjuvant treatments, and even hormonal adjuvant therapy was only given to $38 \%$ of patients. As expected and also highlighted in our report, OS was significantly worse amongst patients $\geq 80$ years with breast cancer. Sanguinetti et al reported $10 \%$ early surgical mortality in their cohort of elderly patients aged $70-95$ years ${ }^{13}$.

An interesting report highlighting the prevalence of clinically relevant comorbidities in elderly ( $\geq 70$ years of age) breast cancer patients undergoing surgical therapy has been published by Gironés and collaborators. They found that the elderly patients had high Charlson comorbidity scores, were frequently frail and/or suffering from geriatric syndromes limiting IADL, and had high rates of polymedication. Increased age was significantly correlated 
with worsening performance status as well as worsening function More than $75 \%$ of the series had a Charlson score $\geq 4$ (ref. $\left.{ }^{14}\right)$.

An analysis with very similar results has been published by Girre at al. One of the most frequent comorbidities in their patients with a median age of 79 years was depression, present or suspected in $53 \%$ of patients. Depression in particular is an example of a condition which will not be recognised in many patients without focussed screening ${ }^{15}$.

Frail patients with associated comorbidities and especially, impaired cognitive function are the subgroup with highest risk of cancer treatment-related complications. The question of treatment individualization is thus highly relevant for the elderly patients with breast cancer.

In the present cohort, the Charlson comorbidity index was the strongest predictor of survival aside from age. Its importance is underlined by the fact that it was not used primarily for treatment decision-making. Therefore, our report suggests the utility of the Charlson score evaluating elderly patients with LABC for more aggressive treatment strategies.

Despite the common occurrence of $\mathrm{LABC}$ in the elderly population of patients with breast cancer, few reports can be found dealing with the subject. These studies, mostly by Italian groups point to the relatively poor prognosis and heterogeneity of this group of breast cancer patients $^{16-18}$. Randomised trials to ascertain the optimal management of elderly patients with LABC are unlikely to be ever carried out.

The question of cancer-specific mortality in the elderly is an important one and has attracted the attention of several authors. Schonberg et al. found that although cardiovascular disease is the most common cause of death in women $\geq 80$ years diagnosed with stage II breast cancer, $63 \%$ of women of the same age diagnosed at stage III or IV died of breast cancer. The cancer-specific mortality of $59 \%$ in the present cohort of stage III patients is consistent with these results ${ }^{19}$.

Similarly, A population-based study of patients in the SEER database revealed that the risk of dying from breast cancer increases with age in elderly women with stage III cancer, peaking in patients $\geq 80$ years of age, a trend also detected in our cohort ${ }^{20}$.

In the cohort reported by Yancik et al only $10 \%$ of 1312 women were diagnosed in stage III or IV. Although specific mortality data for elderly stage III patients are not provided and less than half of deaths in patients $\geq 75$ were caused by breast cancer, the overall mortality in patients with stage III disease was eight times higher than that in stage I patients ${ }^{21}$.

These reports in agreement with our findings indicate that while non-cancer causes are the dominant cause of mortality in elderly women diagnosed with early-stage breast cancer, cancer becomes more prominent as a cause of death in advanced disease stages.

The limitations of the current study are inherent to its retrospective character. We cannot exclude selection bias based on clinical impression which cannot be parametrised. Although the present cohort of elderly patients with $\mathrm{LABC}$ is among the largest reported in the literature, low numbers of patients with specific clinical characteristics precluded us from carrying out more detailed comparisons, especially in patients over 80 years. Formal comprehensive geriatric assessment was not carried out as the test is still not supported by sufficient evidence to be implemented in routine clinical practice ${ }^{22}$.

\section{CONCLUSION}

The present study shows that LABC in elderly patients is associated with poor prognosis. Most deaths in the described cohort were cancer-related although non-cancer related deaths constituted an important proportion of mortality despite advanced stage of breast cancer at presentation. Locoregional therapies were less likely to be applied in patients $\geq 80$ years, probably due to high prevalence of severe comorbidities reflected in the Charlson score. Prospective studies in this age group are needed to optimise treatment strategies and outcomes.

Acknowledgement: Publication costs were covered by a grant from Roche to the First Faculty of Medicine, Charles University, Prague, Czech Republic. Supported by grant RVO Thomayer Hospital TN 0064190 from the Ministry of Health, Czech Republic.

Author contributions: JH, TB: study design and manuscript writing; JH, JA, DK, ZD, MK, LB, JD, RZ, TB: patient and data acquisition; $\mathrm{ZB}$, PM: data processing and statistical analysis; all authors: final approval.

Conflict of interest statement: None declared.

\section{REFERENCES}

1. Dusek L, Muzik J, Kubasek M, Koptiková J, Zaloudik J, Vyzula R. Epidemiology of Malignant Tumours in the Czech Republic [online]. Masaryk University, Czech Republic, [2005], [accessed 20167-03]. http://www.svod.cz.

2. Grumpelt AM, Ignatov A, Tchaikovski SN, Burger E, Costa SD, Eggemann $\mathrm{H}$. Tumor characteristics and therapy of elderly patients with breast cancer. J Cancer Res Clin Oncol 2016;142:1109-16.

3. Bergman L, Kluck HM, van Leeuwen FE, Crommelin MA, Dekker G, Hart AA, Coebergh JW. The influence of age on treatment choice and survival of elderly breast cancer patients in south-eastern Netherlands: a population-based study. Eur J Cancer 1992;28A:1475-80.

4. Audisio RA, Bozzetti F, Gennari R, Jaklitsch MT, Koperna T, Longo WE, Wiggers T, Zbar AP. The surgical management of elderly cancer patients: recommendations of the SIOG surgical task force. Eur J Cancer 2004;40:926.

5. Biganzoli L, Wildiers H, Oakman C, Marotti L, Loibl S, Kunkler I, Reed M, Ciatto S, Voogd AC, Brain E, Cutuli B, Terret C, Gosney M, Aapro $M$, Audisio R. Management of elderly patients with breast cancer: updated recommendations of the International Society of Geriatric Oncology (SIOG) and European Society of Breast Cancer Specialists (EUSOMA). Lancet Oncol 2012;13:e148-60.

6. Bastiaannet E, Liefers GJ, de Craen AJ, Kuppen PJ, van de Water W, Portielje JE, van der Geest LG, Janssen-Heijnen ML, Dekkers OM, van de Velde CJ, Westendorp RG. Breast cancer in elderly compared to younger patients in the Netherlands: stage at diagnosis, treatment and survival in 127805 unselected patients. Breast Cancer Res Treat 2010;124:801-7.

7. Eaker S, Dickman PW, Bergkvist L, Holmberg L. Differences in management of older women influence breast cancer survival: results from a population-based database in Sweden. PLoS Med 2006;3:e25. 
8. Owusu C, Lash TL, Silliman RA. Effect of undertreatment on the disparity in age-related breast cancer-specific survival among older women. Breast Cancer Res Treat 2007;102:227-36.

9. Kristjansson SR, Wyller TB. Introduction, ESMO handbook of cancer in senior patients, editors Schrijvers D, Aapro M, Zakotnik B, Audisio $\mathrm{R}$, Halteren $\mathrm{H}$, Hurria $\mathrm{H}$, Informa healthcare, New York - London, $\mathrm{p}$. 1-7, 2010.

10. Charlson ME, Pompei $\mathrm{P}$, Ales $\mathrm{KL}$, MacKenzie CR. A new method of classifying prognostic comorbidity in longitudinal studies: development and validation. J Chronic Dis 1987;40:373-83.

11. Diab SG, Elledge RM, Clark GM. Tumor characteristics and clinical outcome of elderly women with breast cancer. J Natl Cancer Inst 2000;92:550-6.

12. Orucevic A, Curzon M, Curzon C, Heidel RE, McLoughlin JM, Panella T, Bell J. Breast Cancer in Elderly Caucasian Women-An Institution-Based Study of Correlation between Breast Cancer Prognostic Markers, TNM Stage, and Overall Survival. Cancers (Basel) 2015;7:1472-83.

13. Sanguinetti $A$, Ragusa $M$, De Falco $M$, Sperlongano $P$, Calzolari $F$, Parmeggiani D, Misso C, Piatto A, Parmeggiani U, Avenia N. Locally advanced breast cancer in elderly patients: treatment standardised or tailored to individual needs? Chir Ital 2007;59:829-33.

14. Gironés R, Torregrosa D, Díaz-Beveridge R. Comorbidity, disability and geriatric syndromes in elderly breast cancer survivors. Results of a single-center experience. Crit Rev Oncol Hematol 2010;73:236-45

15. Girre V, Falcou MC, Gisselbrecht M, Gridel G, Mosseri V, Bouleuc
C, Poinsot R, Vedrine L, Ollivier L, Garabige V, Pierga JY, Diéras V, Mignot L. Does a geriatric oncology consultation modify the cancer treatment plan for elderly patients? J Gerontol A Biol Sci Med Sci 2008;63:724-30.

16. Solej M, Ferronato M, Nano M. Locally advanced breast cancer in the elderly: curettage mastectomy. Tumori 2005;91:321-4.

17. Brancato G, Gandolfo L, Privitera A, Donati M, Amodeo C. Locally advanced breast cancer in the elderly: a major challenge requiring effective and appropriate treatment. Tumori 2002;88:467-9.

18. Ma CD, Chen CM, Chen XS, Liu GY, Di GH, Wu J, Lu JS, Yang WT, Chen JY, Shao ZM, Shen ZZ, Shen KW.Neoadjuvant chemotherapy with vinorelbine-containing regimens in elderly patients with locally advanced breast cancer. Anticancer Res 2008;28:3093-7.

19. Schonberg MA, Marcantonio ER, Ngo L, Li D, Silliman RA, McCarthy EP. Causes of death and relative survival of older women after a breast cancer diagnosis. J Clin Oncol 2011;29:1570-7.

20. Chen HL, Zhou MQ, Tian W, Meng KX, He HF. Effect of Age on Breast Cancer Patient Prognoses: A Population-Based Study Using the SEER 18 Database. PLoS One 2016;11:e0165409.

21. Yancik R, Wesley MN, Ries LA, Havlik RJ, Edwards BK, Yates JW. Effect of age and comorbidity in postmenopausal breast cancer patients aged 55 years and older. JAMA 2001;285:885-92.

22. Parks RM, Lakshmanan R, Winterbottom L, Al Morgan D, Cox K, Cheung KL. Comprehensive geriatric assessment for older women with early breast cancer - a systematic review of literature. World J Surg Oncol 2012;10:88. 